Preprints of the

Max Planck Institute for

Research on Collective Goods

Bonn 2010/34

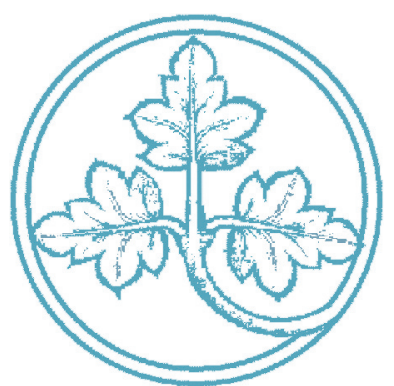

The More the Better?

Effects of Training and Information Amount in Legal Judgments

Stephan Dickert

Britta Herbig

Andreas Glöckner

Christina Gansen

Roman Portack

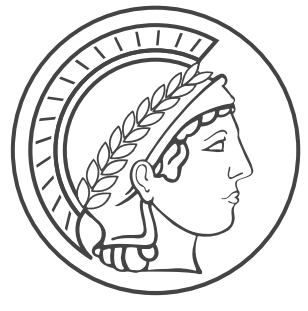




\section{The More the Better?}

\section{Effects of Training and Information Amount in Legal Judgments}

Stephan Dickert, Britta Herbig, Andreas Glöckner,

Christina Gansen \& Roman Portack

August 2010 


\title{
The More the Better? \\ Effects of Training and Information Amount in Legal Judgments ${ }^{1}$
}

\author{
Stephan Dickert ${ }^{2}$, Britta Herbig ${ }^{3}$, Andreas Glöckner ${ }^{4}$, \\ Christina Gansen ${ }^{5}$ \& Roman Portack ${ }^{6}$
}

\begin{abstract}
In an experimental study we investigated effects of information amount and legal training on the judgment accuracy in legal cases. In a two (legal training: yes vs. no) x two (information amount: high vs. low) between-subjects design, 90 participants judged the premeditation of a perpetrator in eight real-world cases decided by the German Federal Court of Justice. Judgment accuracy was assessed in comparison with the Court's ruling. Legal training increased judgment accuracy, but did not depend on the amount of information given. Furthermore, legal training corresponded with higher confidence. Interestingly, emotional reactions to the legal cases were stronger when more information was given for individuals without legal training but decreased for individuals with training. This interaction seems to be caused by fundamental differences in the way people construct their mental representations of the cases. We advance an information processing perspective to explain the observed differences in legal judgments and conclude with a discussion on the merits and problems of offering more information to lay people participating in legal decision making.
\end{abstract}

1 We kindly thank Robert Mauro for helpful discussions on an earlier draft and Janet Kleber for help with manuscript preparation. Correspondence concerning this article should be addressed to Stephan Dickert, Max Planck Institute for Research on Collective Goods, Kurt Schumacher Str. 10, D-53113 Bonn, Germany. E-mail: dickert@coll.mpg.de

2 Max Planck Institute for Research on Collective Goods, Bonn, Germany

3 Institute for Occupational, Social and Environmental Medicine, Ludwig-Maximilians-University, Munich, Germany

4 Max Planck Institute for Research on Collective Goods, Bonn, Germany

5 University of Bonn, Germany

6 University of Bonn, Germany 


\section{Introduction}

A fundamental task for legal decision makers (e.g., jurors or judges) is to make just and coherent judgments. In making these judgments, usually an abundance of information about the specifics of the case at hand has to be processed. It is commonly agreed upon that the underlying information processing of legal judgments should be unbiased and not influenced by factors that are exogenous and unrelated to the judgment task. However, there is a large literature indicating irrational influences. It has been shown, for example, that legal judgments depend on whether they are made in foresight or with knowledge of what happened in hindsight (Hastie, Schkade, \& Payne, 1999), that information is reevaluated in the decision process to fit better with the preferred verdict (Carlson \& Russo, 2001; Simon, 2004; Simon, Snow, \& Read, 2004), that irrelevant information changes the degree of penalty (Englich, 2005; Englich, Mussweiler, \& Strack, 2006), and that mood has an influence on the verdict (Englich \& Soder, 2009). These biases have been demonstrated for people with and without legal training (e.g., Guthrie, Rachlinski, \& Wistrich, 2007), and judges with legal training showed a smaller magnitude for only a few of them (see Guthrie, Rachlinski, \& Wistrich, 2000). While the impact of these biases may be slightly reduced by legal training, their influence on untrained individuals participating in legal court proceedings (i.e., jurors) might be particularly disconcerting given the prominent role ascribed to these individuals. Untrained legal decision makers are used in various functions in different legal systems (Ma, 1998). For example, in the US jurors fulfill the role of a community member judging the guilt of the defendant who is charged with a crime she (possibly) committed in that community. In the German legal system, lay judges are used in order to judge legal cases together with trained professionals (i.e., professional judges) in some legal courts (Machura, 2001, 2007). In both of these examples, lay judges are given little or no training in legal discourse but are tasked with judging the guilt of a defendant. More often than not, these judgments rest on how judges process the relatively complex material presented during the trial.

The different approaches of trained vs. untrained legal decision makers could, however, be a cause for concern and encourage a closer look at how training influences information processing and judgments in court. According to approaches explaining the development of expertise (see Holyoak, 1991, for an overview), legal training and experience influence the processing of information in complex ways (Blasi, 1995; Marchant \& Robinson, 1999; Spellman, 2010) resulting in improved judgment quality (but see also below). It has been shown that with intense training people develop complex knowledge structures that help them process large amounts of information (Chase \& Simon, 1973). A common assumption for decision making has been that deliberative information processing together with more complete information leads to better decisions (e.g., Shafir, Simonson, \& Tversky, 1993). This should especially be the case in the legal realm, where we would hope that having all information available produces the fairest result of a trial. However, it is unclear whether more information leads to better legal decisions for untrained people, as they might not be able to 
process the information due to limited cognitive capacity and the fact that they lack specific knowledge structures that help them handle the increased amount of information. Moreover, due to their limited knowledge about legal decision making, untrained persons might be more susceptible to dilution effects (i.e., impact of diagnostic information on judgments and decision making is reduced when additional, non-diagnostic information is presented; cf. Nisbett, Zukier, \& Lemley, 1981; Zukier, 1982). Persons with legal training should be better equipped to sort between legally relevant and irrelevant information.

Differences in the mental processes underlying judgments of trained vs. untrained legal decision makers likely rest on the different knowledge structures they can draw upon when considering the legal information presented. Whereas untrained judges often have to rely on their general knowledge to weigh evidence and decide whether a defendant is guilty of breaking the law, trained judges are expected to consult their complex theoretical knowledge and an abundance of practical experience (Blasi, 1995; Klein, 1993; Spellman, 2010; see also Kahneman \& Klein, 2009). This expertise and the level of training is commonly thought to influence decision quality and judgment accuracy (e.g., correct appraisal of the evidence and appropriate confidence in their judgments) by helping trained legal professionals to process complex legal information more effectively. Research on expertise and decision making has shown that experts exhibit high, outstanding, and exceptional performance which is domainspecific, stable over time, and related to knowledge, experience and practice (cf. Sonnentag, 2000). However, the influence of legal training or legal expertise has been investigated only sporadically in expertise research (e.g., Marchant, Robinson, Anderson, \& Schadewald, 1991, 1993; Nievelstein, van Gog, Boshuizen, \& Prins, 2010). Nievelstein et al. (2010) showed that conceptual knowledge acquired by training is essential for solving legal cases, and also for efficiently using additional materials (e.g., lawbooks). Decision processes of legally trained vs. untrained persons in a domain with high density, relevance and public visibility of decisions need careful study to better understand the underlying mechanisms and mental representations leading to accurate judgments. Besides superior knowledge, factors that might differ for trained and untrained people making legal judgments are the ability to handle more and more complex information, the mental representation of legal information, confidence in one's own judgments, and emotional reactions to the content of the legal scenarios.

Training in a specific domain typically leads to more efficient information processing and to better judgments (e.g., Reyna \& Lloyd, 2006; Ste-Marie, 1999). Training in legal decision making should therefore result in better selection and weighting of the available information. This efficiency should lead individuals with legal training to be able to handle more (and more complex) information better than individuals without legal training. Complexity can be defined as tasks, situations etc. that contain a high amount of information with manifold interrelations between them (e.g., Dörner \& Schaub, 1994). Legal decision making is in most parts a highly complex task: For example, a judge not only has to consider information from a case, but also the laws and the interdependency between both (e.g., whether certain laws are 
applicable in a certain case or not). Research has shown that experts usually fare better in adapting to and dealing with complexity than novices (e.g., Haerem \& Rau, 2007). Their knowledge is more complete, contains less incorrect parts, and is better integrated (e.g., Büssing \& Herbig, 2003; Sonnentag, 2000).

A direct consequence of the differences in knowledge and information search of people with and without domain specific training is a difference in the way complex tasks are mentally represented - both structurally and in terms of content. It is, for example, reasonable to assume that people without legal training do not represent a crime in terms of legal categorizations while people with legal training could be expected to do just that. Moreover, concepts like encapsulated knowledge (e.g., Boshuizen \& Schmidt, 1992) or chunking (e.g., Lesgold, Rubinson, Feltovich, Glaser, Klopfer, \& Wang, 1988) refer to structural dissimilarities depending on expertise; that is, people with training and experience being able to store large quantities of information as one chunk but having access to all information if the necessity for a more detailed mental representation arises. Moreover, mental representations should mirror the differences between trained and untrained individuals in perceiving complexity (Haerem \& Rau, 2007) and give rise to judgment confidence and emotional responses to the information.

The confidence in a legal judgment is an important part in good legal decision making as it serves as an internal check for the quality in the judgment. When confidence is low, additional information might be sought or the presented information weighted in a different way to produce greater confidence in one's judgment (cf. Glöckner \& Betsch, 2008). When information is processed in a way that establishes a coherent mental representation of the legal material (e.g., a clear mental image of the sequence of events in a crime), confidence is usually higher (Holyoak \& Simon, 1999). Lichtenstein and Fischhoff (1977) showed that people and especially experts - tend to be overconfident in their judgments in probability tasks (also Goodman-Delahunty, Granhag, Hartwig, \& Loftus, 2010, for legal case predictions). It has been demonstrated that overconfidence is one of the downsides of bi-directional reasoning and story-construction processes that are used for solving legal cases (e.g., Holyoak \& Simon, 1999; Simon, 2004; Read, Vanman, \& Miller, 1997, see also Pennington \& Hastie, 1986, 1988, 1992). That is, in striving for coherence in the mental representation (or mental model) of the case, the validity of initial information changes in the direction of the emergent interpretation, which in turn leads to higher confidence in the judgment. "[T]he greater the transformations of the mental models, the higher the confidence experienced" (Simon, 2004, p. 533). Greater knowledge in a specific domain and a more coherent mental model could therefore result in greater confidence.

Emotional responses to a case also depend on the underlying information processes and the mental representation of the case (e.g., Ask \& Granhag, 2007). It is not uncommon that the content of criminal cases evokes strong emotional reactions as violations of laws are often also violations against social or moral norms, which have the potential to evoke strong emo- 
tional reactions (e.g., anger, disgust, etc.). Moreover, laws accommodate for emotions to be causally related to criminal actions (e.g., crimes of passion are treated differently than coldblooded crimes). The link between emotional responses to criminal behavior and legal judgments is therefore not new, but has been an integral part of jurisdiction (Feigenson \& Park, 2006). It is of note that emotional responses of judges to legal material are generally seen as a source of bias that degrade judgment quality. This may stem from the common belief that legal decision making should be rule-based and built on careful deliberative analysis void of emotion However, the biasing function of emotions may depend on the level of legal training (Englich \& Soder, 2009; Wessel, Drevland, Eilertsen, \& Magnussen, 2006). If legal training leads to better calibrated mental representations and information processing, then we would expect individuals with such training to neglect biasing emotional responses or even to be able to build mental representations of the task that are based on abstract categories that do not evoke emotional responses at all.

Research on judgment and decision making provides plenty of evidence that emotions (Bechara, Damasio, Tranel, \& Damasio, 1997; Finucane, Alhakami, Slovic, \& Johnson, 2000; Luce, Bettman, \& Payne, 1997; Luce, Payne, \& Bettman, 1999, 2001; Naqvi, Shiv, \& Bechara, 2006) and the amount of information to process (Dijksterhuis, Bos, Nordgren, \& van Baaren, 2006; Payne, Bettman, \& Johnson, 1992) strongly influence decision processes (e.g., Feigenson \& Park, 2006). Contrary to the assumption that emotions degrade decision performance, research has also shown the merits of emotions in good decision making (e.g., Dickert \& Peters, under review; Schwarz, 2002; Schwarz \& Clore, 1983; Slovic, Finucane, Peters, \& MacGregor, 2002). In legal scenarios, this might depend in large part on the type of emotional response and its match with the legal standard. For example, a particularly heinous crime might evoke negative emotions that are actually in accord with ruling against the defendant. The interesting question is whether individuals trained (vs. untrained) in legal studies develop different emotional responses or whether they screen the information without reacting affectively.

In the present experiment we used legal cases recently decided by the German Federal Court of Justice to investigate the effects of amount of case-information (as one part of complexity) and legal training on the quality of legal judgments, confidence in the accuracy of those judgments, and emotional responses to the case material. Specifically, we manipulated the amount of information that people with and without legal training had to process by giving additional information about the legal case in question. Using cases already decided by the German Federal Court of Justice provided us with an outside criterion for judgment accuracy. 


\section{Hypotheses}

\section{Judgment accuracy}

We expected that the accuracy of legal judgments depends on legal experience, such that individuals with advanced legal training would outperform those without training (H1a). Providing more information should make it more difficult to focus on the relevant parts, resulting in degraded judgment accuracy (H1b). However, the negative effect of information amount likely depends on legal training, such that individuals with legal training should be better able to deal with a higher amount of information than individuals without training (H1c).

\section{Confidence}

We hypothesized that individuals with legal training would be more confident in their judgments (H2a). Consistent with hypothesis $\mathrm{H} 1 \mathrm{c}$, we also predict that for individuals with legal training more information would lead to higher confidence whereas the opposite effect would be observed for individuals without legal training (H2b).

\section{Emotions}

We expected that individuals with legal training process and integrate information in categories that accord with their existing legal knowledge, resulting in less emotional reactions (H3a). Additionally, we expected legal cases with more information to lead to more vivid mental representations of the crimes and thereby increasing emotional reactions (H3b). However, this effect might be particularly driven by individuals without legal training $(\mathrm{H} 3 \mathrm{c})$.

\section{Method}

\section{Participants and Design}

Ninety students from the University of Bonn participated in this study which was part of a 2 hour experimental battery with other studies on unrelated topics. The sample consisted of 49 male and 41 female participants, with ages ranging from 19 to $53(M=24.1, S D=4.48)$. Fifty were law students with advanced legal training (5th to 12th semester) with the majority being shortly before the final bar exams (67\% 7th semester and higher) and the other 40 participants were students of other subjects in various stages of their studies. The sample of advanced law students consisted of 19 females and 31 males, ranging from 22 to 30 years $(M=23.8, S D=1.39)$ in age; the lay sample comprised 22 females and 18 males, with ages ranging from 19 to 53 years $(M=24.4, S D=6.5)$. A manipulation check of self-rated experi- 
ence with legal topics in general $\left(1=\right.$ no experience at all, $5=$ expert; $M_{\text {trained }}=3.5 ; S D_{\text {trained }}=$ $\left..51 ; M_{\text {untrained }}=1.7 ; S D_{\text {untrained }}=.51\right)$, criminal law $\left(M_{\text {trained }}=3.2 ; S D_{\text {trained }}=.63 ; M_{\text {untrained }}=1.6\right.$; $\left.S D_{\text {untrained }}=.60\right)$ and theories of premeditation $\left(M_{\text {trained }}=2.8 ; S D_{\text {trained }}=.79 ; M_{\text {untrained }}=1.5\right.$; $S D_{\text {untrained }}=.60$ ) supported their assignment to the subsamples (all differences $t>8.0, p<$ $.001)$. Participants were then randomly assigned to one of two information amount conditions (see below). Thus, we used a 2 (advanced legal training: yes vs. no) $\times 2$ (information amount: high vs. low) between-subject design.

\section{Case material}

Cases were selected from the domain of criminal law, specifically cases of manslaughter with the crucial question of premeditation ${ }^{7}$. Real cases documented in legal data bases were researched and selected based on three criteria: First, verdicts of the German Federal Court of Justice regarding the case had to be available (see below). Second, cases had to be recent enough to prevent that participants with advanced legal training might recognize them from their studies. And third, cases should not be too complex in order to allow a case summary of about half a page without loosing critical information. From the available material eight cases were chosen (see appendix for a detailed example): A landlord causing a gas explosion and killing tenants, a deadly fight after a visit to the pub, a robbery at a newsstand, child abuse under the influence of alcohol, a rape attempt after an evening spent together, a shooting by a homeless person, aggressive driving leading to a serious accident, and rape and robbery with fatal consequences. All cases were then condensed and structured in the same way: Description of offender, victim and their relation followed by an account of the sequence of events, and finally, a statement on the harm done to the victim. After reading each case, participants had to answer the question if the offender's action was premeditated or not. The sequence of the cases followed a fixed randomized order.

\section{Information amount}

As detailed above, judgments of persons with different levels of legal training should be influenced differentially by the amount of available case information. Each selected case was prepared in two different versions: one with less information containing 11 to 13 basic propositions (as a measure of information content) and the other with more information comprising 20 to 24 propositions. Version 2 was exactly identical to Version 1 except for the additional propositions. A critical point was that these additional pieces of information were chosen from the original case material but followed the main objective to be not more informative

German law does not use different terms for intentionality in different types of offenses. As five out of eight cases involve a killing we will use the term "premeditation" in the remainder of the paper although three cases describe non-lethal assaults. 
for answering the question of premeditation than the basic information. In a pre-test with participants from the same subject pool (containing both student with and without legal training) investigating the relevance and validity of the propositions, we found that the basic propositions were rated significantly more relevant to the premeditation judgment than the additional propositions, $F(1,70)=28.7, p<.001, \eta^{2}=.29$. Moreover, the additional propositions were rated as being less valid cues for the judgment than basic propositions, $F(1,70)=14.9$, $p<$ $.001, \eta^{2}=.18$. Also, this main effect was stable for both trained and untrained participants of the pre-test, as a non-significant interaction showed, $F<1, p>.367$, verifying that any effects of information content are not due to differential validity of the additional propositions.

\section{Materials and Procedure}

Participants were randomly selected to receive one of the two versions (high vs. low amount of information). After reading each case material, participants had to decide if the offender's crime was premeditated or not and indicate on an 11-point Likert scale how confident they were of their decision $(0=$ absolutely uncertain, $10=$ absolutely certain $)$. Two items were used to investigate participants' emotions: Emotional arousal and the valence of the experienced emotion. As all cases consisted of crimes against persons, we limited the questions to assess unpleasant activation (i.e., negative valence and high/low arousal). On 11-point Likert scales, we asked participants How strongly are you affected by this case? $(0=$ not at all, $10=$ very strongly) and How negative is your emotional reaction to this case? $(0=$ neutral, $10=$ very negative). As the internal consistency of these items was very high (Cronbach's $\alpha$ between .72 and .89 for individual cases; overall $\alpha=.96$ ), we pooled them into a single Emotion scale. To get a first impression on the mental representations of the cases, we asked participants at the end of the experiment if the cases were evocative of a specific mental picture and to briefly describe it. These qualitative data were then coded and analyzed (see result section).

\section{Results}

\section{Judgment accuracy}

Since our research questions concern judgment accuracy, we used the verdicts of the German Federal Court of Justice (the highest appellate court in Germany for civil and criminal cases) on the question of premeditation in each of the eight cases as an external criterion for participants' accuracy. Accurate judgments were thus operationalized as "hits" (premeditation was present) or correct rejections (premeditation was not present). Descriptive data on accuracy show that legal training resulted in more accurate judgments in general, and that this does not seem to depend on information amount (see Figure 1a). To test our hypotheses, we conducted a logistic regression predicting accuracy with legal training, amount of information, and the 
interaction between the two predictors. Additionally, dummy variables were included to control for case-specific variance. In this and all following regressions we corrected for clusters in observations due to repeated measurement and violations of homoscedasticity using STATA standard procedures (i.e., CLUSTER, ROBUST; Gould, Pitblado, \& Sribney, 2006; Hayes \& Cai, 2007; Rogers, 1993). Not surprisingly and in support of H1a, we found that legal training predicts better judgment accuracy (Table 1). In line with the descriptive data, the results indicate that individuals with legal training were more likely to judge a case correctly than individuals without legal training. The odds ratio indicates that the ratio of the odds of being correct as compared to wrong is for people with legal training 1.8 as high as for people without legal training. Stated differently, the marginal effect of legal training is $14 \%$. However, varying the amount of information did not produce differential accuracy (H1b). We also did not find evidence for an interaction effect (H1c), suggesting that individuals with legal training did not benefit differentially from additional information compared to individuals without legal training.

Table 1: Logistic Regression for Judgment Accuracy

\begin{tabular}{lc}
\hline & $\begin{array}{c}\text { Judgment } \\
\text { Accuracy }\end{array}$ \\
\hline Amount of information & 0.868 \\
$(1=$ high vs. $0=$ low $)$ & $(-1.19)$ \\
Legal training & $1.800^{\star \star \star}$ \\
$(1=y e s$ vs. $0=$ no $)$ & $(4.90)$ \\
& \\
IE Amount * Training & 0.869 \\
\hline Observations & $(-0.58)$ \\
Pseudo $R^{2}$ & 719 \\
\hline
\end{tabular}

Exponentiated coefficients; SEs corrected for 90 clusters in observations due to repeated measurement; $z$ statistics in parentheses

*** $p<0.001$ 
Figure 1: The Effects of Legal Training and Information Amount

a) Accuracy

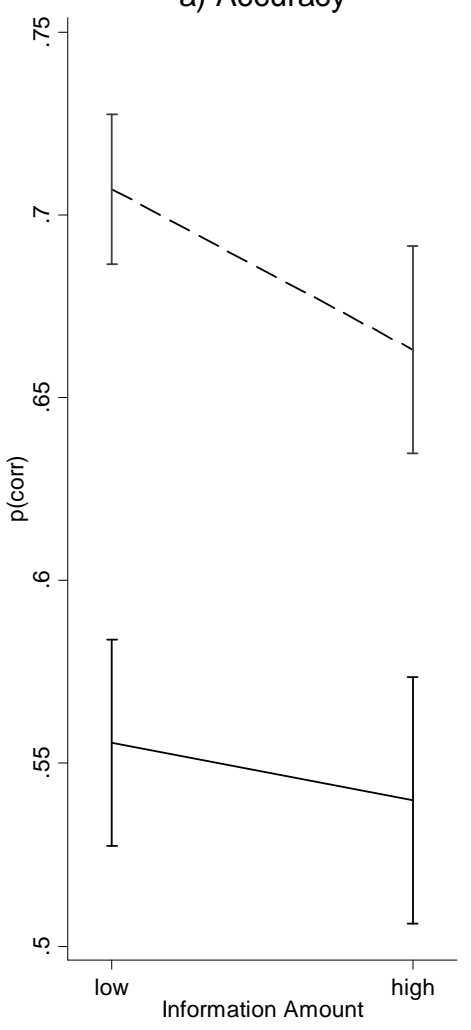

b) Confidence

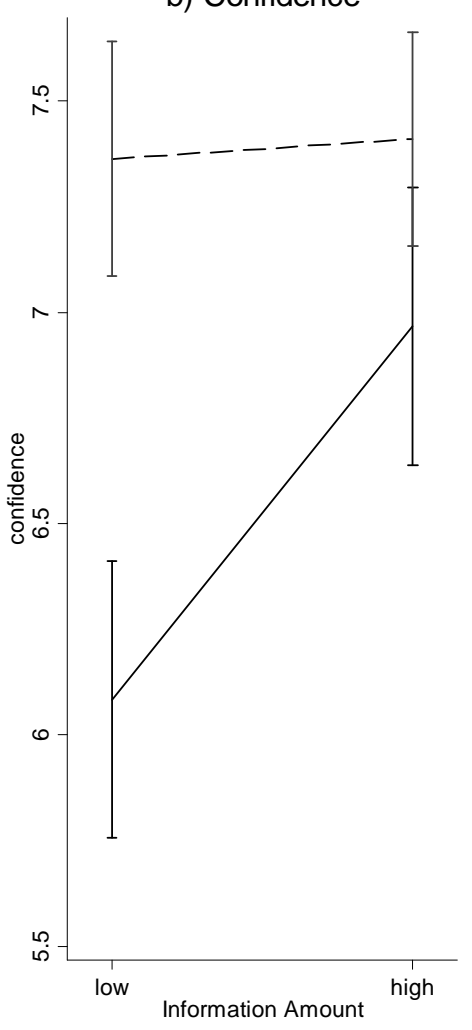

c) Emotional Reaction

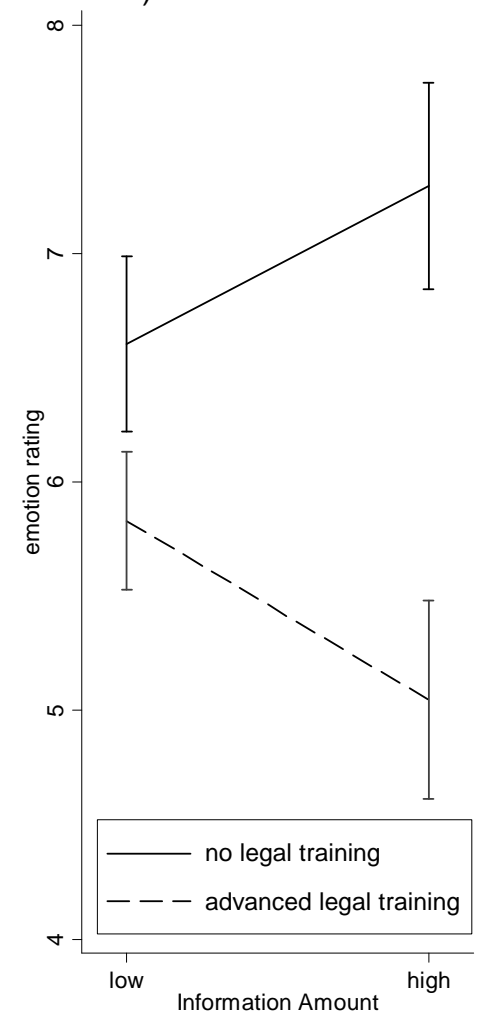

Note. Error bars indicate SEs corrected for clusters in observations due to repeated measurement.

\section{Confidence Ratings}

We expected that confidence would be influenced by legal training in that individuals with legal training should show higher confidence $(\mathrm{H} 2 \mathrm{a})$, which was descriptively supported by the data (Figure 1b). Confidence ratings were analyzed by linear regressions with legal training, amount of information, and the respective interaction as predictors (Table 2). We found support for $\mathrm{H} 2 \mathrm{a}$ in that legal training (vs. no legal training) corresponded to higher confidence in participants' judgments. However, neither the interaction nor the main effect for information amount reached conventional significance levels. Thus, we did not find support for $\mathrm{H} 2 \mathrm{~b}$, which suggests that individuals with legal training do not become more confident with increasing information. In fact, the data descriptively looks like individuals without legal training increase their confidence when more information is given, whereas confidence of individuals with legal training is somewhat less affected by varying information amounts. 
Table 2: Linear regression for confidence and emotional ratings

\begin{tabular}{lcc}
\hline & $\begin{array}{c}(1) \\
\text { Confidence }\end{array}$ & $\begin{array}{c}(2) \\
\text { Emotion Rating }\end{array}$ \\
\hline $\begin{array}{l}\text { Amount of Information } \\
\text { (1=high vs. 0=low) }\end{array}$ & 0.418 & -0.128 \\
& $(1.42)$ & $(-0.32)$ \\
Legal Training (1=yes vs. & $0.862^{\star \star}$ & $-1.512^{\star \star *}$ \\
0=no) & $(2.88)$ & $(-3.80)$ \\
IE Amount*Training & -0.836 & $-1.475^{\star}$ \\
& $(-1.40)$ & $(-1.85)$ \\
Constant & $7.003^{\star \star *}$ & $6.110^{\star \star *}$ \\
& $(47.59)$ & $(30.90)$ \\
\hline Observations & 718 & 718 \\
Adjusted $R^{2}$ & 0.040 & 0.092 \\
\hline
\end{tabular}

t statistics in parentheses; SEs corrected for 90 clusters in observations due to repeated measurement

$+\mathrm{p}<0.10, * \mathrm{p}<0.05$ (one-tailed), ** $\mathrm{p}<0.01, * * * \mathrm{p}<0.001$

\section{Emotions}

We expected that individuals with legal training would be less emotionally reactive to the content of the cases $(\mathrm{H} 3 \mathrm{a})$, that more information leads to clearer mental representations and stronger emotional reactions $(\mathrm{H} 3 \mathrm{~b})$, and that this latter effect is stronger for individuals without legal training. The data descriptively support all three hypotheses (Figure 1c). To test the hypotheses statistically, we regressed emotional ratings on legal training (yes vs. no), amount of information and the interaction between the two predictor variables (see Table 2). Results show the predicted main effect of legal training $(\mathrm{H} 3 \mathrm{a})$, such that individuals without legal training reported stronger emotional reactions to the legal cases. While we did not find support for the predicted main effect of information amount (H3a), a significant interaction supports our hypothesis in a one-sided test $(\mathrm{H} 3 \mathrm{c})$. Specifically, whereas individuals with legal training reported weaker emotional reactions with increasing amount of information, individuals without legal training indicated stronger emotional reactions when more information was given.

\section{Explorative analysis of mental representations}

To investigate the mental representations underlying confidence ratings and emotional reactions, we conducted an explorative analysis of participants' reported mental representations of the legal case. The qualitative data on the mental representation were coded along a mixed content- and theory-driven code system (cf. Miles \& Huberman, 1984). Each written statement on a case was analyzed for seven different codes that gathered the theme, details and personal involvement in the mental representation. Specifically, each statement was coded whether a legal term was used or not; whether it was general or specific; whether it was ex- 
patiated upon or merely stated; whether self-involvement was stated or not; whether a reference to the offender was made or not; whether a reference to the victim was made or not; and - if applicable - whether a fictitious (e.g., film, TV) or a real-life situation was stated. Overall, 253 statements were given by the participants and coded by two independent raters. After rating the first 50 statements results were compared, differences discussed and the code descriptions refined where necessary. In a second step, all statements were rated anew. Interrater-reliability ranged from good (general or specific: Kendall's $\tau=.68,86.2 \%$ agreement) to very good (self-involvement: Kendall's $\tau=.97,99.6 \%$ agreement).

Figure 2 summarizes the results for the mental models of persons with and without legal training. Three codes show a systematic pattern. As could be expected, legal terms are significantly more often present in the mental representation of individuals with legal training than in the representations of individuals without such training (Mann-Whitney $U=180.5$, exact $p$ $<.001$ ). Moreover, persons without legal training show a higher involvement of self (MannWhitney $U=307.5$, exact $p=.013$ ) and more references to real-life situations (MannWhitney $U=313.0$, exact $p=.050$ ) than participants with legal training. That is, whereas participants with advanced legal training represent cases in more legal (abstract) terms, the cases seem to evoke memories of real situations and a higher personal involvement in people without legal training. Participants with legal training also expatiated more upon the cases than persons without training, however, this effect did not reach conventional significance level (Mann-Whitney $U=337.5$, exact $p=.085$ ).

Figure 2: Differences in mental models between participants with and without legal training

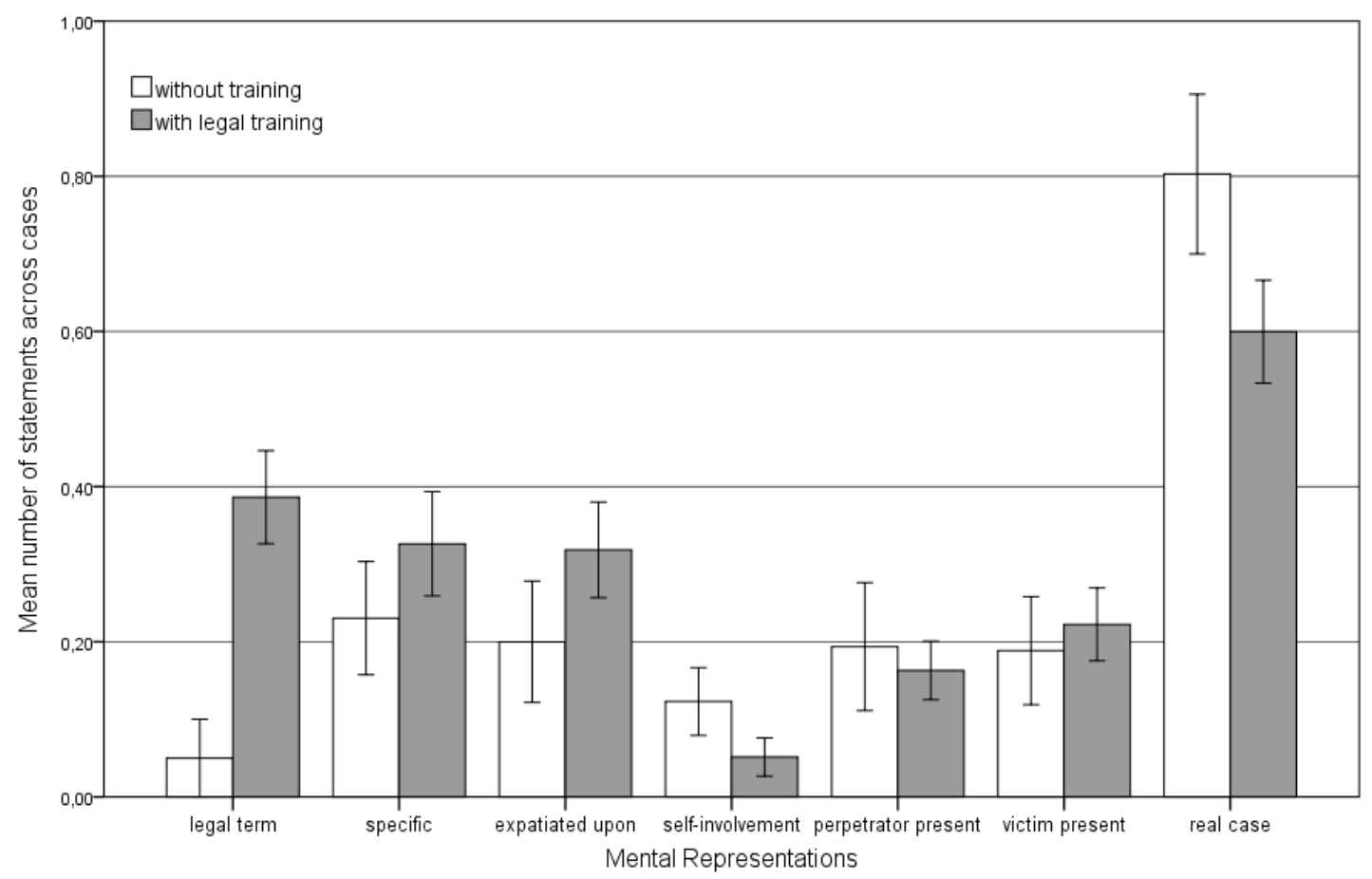

Note. Error bars indicate SEs. 


\section{Discussion}

The current study was designed to investigate the effects of training and information amount on decision quality, confidence and emotional reactions in legal cases concerning premeditation. In contrast to some findings concerning the quality of experts' judgments and decisions (e.g., Shanteau, 1992), we found that persons with legal training are clearly better than persons without training in judgments of premeditation. Hence, our findings are in accord with the majority of expertise research that shows superiority of experts over lay persons concerning performance (see e.g., Sonnentag, 2000). Our data allow generalizing these effects to the field of law. Our next hypotheses, that more information should make it more difficult to focus on the relevant parts, resulting in degraded judgment accuracy and that this effect should depend on legal training, was not supported by the data. That is, a higher amount of information in itself as well as in interaction with the level of legal training, had no influence on the judgment accuracy. This result might partially contradict with results on dilution effects (e.g., Nisbett et al., 1981; Smith, Stasson, \& Hawkes, 1998).

In line with research on (over)confidence (Goodman-Delahunty et al., 2010; Lichtenstein \& Fischhoff, 1977), participants with legal training were more confident in their decisions than participants without training. We also hypothesized that for individuals with legal training more information leads to higher confidence whereas the opposite effect will be observed for individuals without legal training. However, we did not find an interaction with the amount of information.

We had also expected that individuals with legal training would be less emotionally reactive to the content of the legal cases, that more information would lead to stronger emotional reactions driven by clearer mental representations, and that this latter effect would be stronger for individuals without legal training. The main effect for training and the interaction effect were supported by our data. The clear differences in mental representations between legally trained and untrained participants might account for the stronger emotional reaction of untrained persons: Trained persons constructed their mental representation mainly using (abstract) legal concepts whereas untrained persons heavily relied on instances of comparable cases they had heard of before or drawing parallels to instances they experienced themselves (selfinvolvement). The latter is likely to induce stronger affective reactions. Moreover, the lower affective reaction of trained participants seems to support the widely held belief that expert lawyers are less affectively influenced by the material and differ in their decision making from non-experts. Interestingly, we observed a differential effect of amount of information: Trained individuals' emotional reaction towards a case reduced with increasing amounts of information, whereas the emotional arousal for untrained participants increased with more information. Legally trained persons seem to become even more analytic with adding further information whereas the opposite is the case for untrained persons. This difference might be due to the fact that people without legal training are not able to appropriately evaluate the additional information. It is also possible that, as the information amount is augmented, 
trained judges recruit increasingly deliberative processing techniques (i.e., comparing the details of the case with existing knowledge structures relevant to the legal judgment) that abstract the given information to the point where the mental representation of the crime is no longer conducive to extreme emotional reactions.

Overall, our findings highlight the differences in how individuals with and without legal training make decisions in legal cases. Trained persons construct mental representations using legal terms. They analyze the case, and this process likely does not generate strong affective reactions. As a result of their superior legal knowledge they are likely to produce better judgments and are more confident in their decisions. Legally trained persons become less aroused when they have more information to process. In contrast, due to their lack of explicit legal knowledge, untrained persons seem to construct their mental representations mainly on the basis of comparable situations they know. They produce stronger affective reactions, particularly when given more information, and their judgments are considerably worse than those of trained persons.

In line with theoretical considerations (e.g., Herbig \& Glöckner, 2009) and findings from expertise research (for an overview see Ericsson, Charness, Hoffman, \& Feltovich, 2006) our results show that legal training can lead to different mental representations, differences in the accompanying integral emotions (Feigenson \& Park, 2006), and also differences in judgment confidence. Moreover, for people in advanced professional training these representations should be better adapted to the complex reality of the domain (i.e., by containing more specific legal terms) and therefore lead to better judgments as shown in our results.

\section{Limitations and Directions for Further Research}

At first glance it should not be surprising that individuals without legal training did not produce the same level of judgment performance as individuals with legal training. This is obvious since law students are more similar in legal knowledge to the judges of the Federal High Court whose ruling was taken as the standard by which judgment accuracy was assessed. The difference in legal knowledge between the two groups used in this experiment is further amplified by the fact that participants were not provided with a legal definition of premeditation. The observed differences in performance, thus, may also reflect a deeper divide in the understanding of what premeditation means for lay judges vs. trained judges. While it is customary to provide legal instructions to jurors in courts, research shows that only a minority of jurors (31\%) actually understand these instructions (Thomas, 2010). In their function as lay judges, they are employed to legitimize jurisdiction, make laws and legal procedures more transparent and understandable, and represent the common public in the court (e.g., Machura, 2007). Our results show that in absence of a clear definition of premeditation, lay people resort to information processing strategies that are built on different mental representations, which is the key element that needs to be taken into account when comparing legal judgments of 
trained vs. untrained judges. Nonetheless, differences in the conception of premeditation between legal scholars and the common public may create its own set of challenges for public policy makers, and future research should critically investigate the extent to which exogenous beliefs influence legal judgments (e.g., Giner-Sorolla, Chaiken, \& Lutz, 2002) and whether jury instructions can change these beliefs.

As untrained legal decision makers are used in various functions in different legal systems (Ma, 1998 e.g. jurors or lay judges), the presented results are generalizeable particularly for this group. However, our participants with advanced legal training are not to be confused with legal experts, so that the contrast between groups should be interpreted with caution. Nonetheless, our results show that even without extensive legal and practical experience in the courtroom, advanced law students already construct a different mental image and rely less on emotions than on legal knowledge compared to students untrained in legal matters. It is still possible, though, that expert or highly experienced judges show different information processing than participants with advanced legal training. For example, with enough experience emotional reactions to the cases might develop into valid cues for legal judgment or give the expert judge a type of "meta-information" (i.e., knowledge on how to select, interpret, and weight relevant information). These speculations will have to be tested in future research with more experienced participants (i.e., professional judges).

In an effort to increase external and ecological validity over studies that employ fictional legal material, we used real legal cases that were decided by the German Federal Court of Justice. This was done in order to have an external criterion allowing a judgment standard against which our participants' judgments could be categorized into correct and incorrect judgments. However, even this external criterion is not immune to criticism. Judgments of the German Federal Court of Justice are not waterproof; actually, the simple fact that a case ends up in this highest German appellate court means that it went through courts at lower levels and is potentially ambiguous. Furthermore, rulings of the Federal Court of Justice are often hotly contested in legal academia. Nevertheless, the use of an external criterion for evaluating performance is important in researching consequences of training. It might be difficult to find specific criteria of judgment and decision quality in the legal domain in general (e.g., quality of legal argumentation, consistent use of legal theory etc.). However, we feel that our straightforward approach allows for a better insight into differences between legally trained and untrained persons.

\section{Conclusion and Policy Implications}

Our research is a step towards understanding legal judgment and decision making on different levels of expertise. Practical recommendations on public policy related to legal procedures need to take into account that laypersons and people with advanced legal training deal quite differently with legal information. Therefore, legal procedures should differ depending 
on whether judgment rulings are made by jurors, lay judges, magistrates or professional judges. One important issue that policy makers need to resolve is whether lay judges should be given the same (and same amount) of information typically provided to professional judges. In the German court system, lay judges are usually provided with a synopsis of the evidence, whereas their professional colleagues have full access to the incriminating case material. While our data do not necessarily support the conclusion that lay judges are worse at handling more information, they do show that mental images and emotional reactions are sensitive to the amount of information provided. Given the propensity of untrained judges and jurors to have stronger emotional reactions to the case information, it seems questionable whether providing more information always leads to better (and unbiased) legal decisions.

In cases where laws are an instantiation of and based on the values of the common public, it is likely that representative yet untrained judges are quite similar in their legal judgments to their professional counterparts. Here a violation of commonly held beliefs and values may lead to an emotional reaction that is in line with the jurisdiction (i.e., a heinous crime is punished accordingly), thereby strengthening the link between emotions and legal decision making. However, there are also cases in which the intricacies of the law run counter to the general conception of fairness and justice, and the mental representation of the crime differs sharply for trained vs. untrained judges. In these cases it might be better to avoid providing lay judges with an abundance of case information. 


\section{References}

Ask, K., \& Granhag, P. A. (2007). Hot Cognition in Investigative Judgments: The Differential Influence of Anger and Sadness. Law and Human Behavior, 31, 537-551.

Bechara, A., Damasio, H., Tranel, D., \& Damasio, A. R. (1997). Deciding advantageously before knowing the advantageous strategy. Science, 275, 1293-1294.

Blasi, G. L. (1995). What lawyers know - Lawyering expertise, cognitive science, and the function of theory. Journal of Legal Education, 45, 313-397.

Boshuizen, H. P. A., \& Schmidt, H. G. (1992). On the role of biomedical knowledge in clinical reasoning by experts, intermediates and novices. Cognitive Science, 16, 153-184.

Büssing, A., \& Herbig, B. (2003). Implicit knowledge and experience in work and organizations. International Review of Industrial and Organizational Psychology, 18, 239-280.

Carlson, K. A., \& Russo, J. E. (2001). Biased interpretation of evidence by mock jurors. Journal of Experimental Psychology: Applied, 7, 91-103.

Chase, W. G., \& Simon, H. A. (1973). Perception in chess. Cognitive Psychology, 4, 55-81.

Dickert, S., \& Peters, E. (under review). Matching Task and Processing Characteristics: Some evidence for the roles of deliberation and affect in repeated decisions.

Dijksterhuis, A., Bos, M. W., Nordgren L. F., \& van Baaren R. B. (2006). On Making the Right Choice: The Deliberation-Without-Attention Effect. Science, 311, 1005-1007.

Dörner, D., \& Schaub, H. (1994). Errors in planning and decision-making and the nature of human information processing. Applied Psychology: An International Review, 43, 433453.

Englich, B. (2005). "Give him five years!" - Influences of partisan hecklers on judges' sentencing decisions. Zeitschrift fuer Sozialpsychologie, 36, 215-225.

Englich, B., Mussweiler, T., \& Strack, F. (2006). Playing dice with criminal sentences: The influence of irrelevant anchors on experts' judicial decision making. Personality and Social Psychology Bulletin, 32, 188-200.

Englich, B., \& Soder, K. (2009). Moody experts - How mood and expertise influence judgmental anchoring. Judgment and Decision Making, 4, 41-50.

Ericsson, K. A., Charness, N., Hoffman, R. R., \& Feltovich, P. J. (Eds.). (2006). The Cambridge handbook of expertise and expert performance. Cambridge: Cambridge University Press. 
Feigenson, N., \& Park, J. (2006). Emotions and attributions of legal responsibility and blame: A research review. Law and Human Behavior, 30, 143-161.

Finucane, M. L., Alhakami, A., Slovic, P., \& Johnson, S. M. (2000). The affect heuristic in judgments of risks and benefits. Journal of Behavioral Decision Making, 13, 1-17.

Giner-Sorolla, R., Chaiken, S., \& Lutz, S. (2002). Validity beliefs and ideology can influence legal case judgments differently. Law and Human Behavior, 25, 507-526.

Glöckner, A., \& Betsch, T. (2008). Modeling option and strategy choices with connectionist networks: Towards an integrative model of automatic and deliberate decision making. Judgment and Decision Making, 3, 215-228.

Goodman-Delahunty, J., Granhag, P. A., Hartwig, M., \& Loftus, E. F. (2010). Insightful or wishful: Lawyers' ability to predict case outcomes. Psychology, Public Policy, and Law, 16, 133-157

Gould, W., Pitblado, J., \& Sribney, W. (2006). Maximum Likelihood Estimation with Stata (3rd ed.). College Station, TX: Stata Press.

Guthrie, C., Rachlinski, J. J., \& Wistrich, A. J. (2000). Inside the judicial mind. Cornell Law Review, 86, 777-830.

Guthrie, C., Rachlinski, J. J., \& Wistrich, A. J. (2007). Blinking on the bench: How judges decide cases. Cornell Law Review, 93, 1-44.

Haerem, T., \& Rau, D. (2007). The influence of degree of expertise and objective task complexity on perceived task complexity and performance. Journal of Applied Psychology, $92,1320-1331$.

Hastie, R., Schkade, D. A., \& Payne, J. W. (1999). Juror judgments in civil cases: Hindsight effects on judgments of liability for punitive damages. Law and Human Behavior, 23, 597-614.

Hayes, A. F., \& Cai, L. (2007). Using heteroskedasticity-consistent standard error estimators in OLS regression: An introduction and software implementation. Behavior Research Methods, 39, 709-722.

Herbig, B., \& Glöckner, A. (2009). Experts and Decision Making: First steps towards a unifying theory of decision making in novices, intermediates and experts. (Preprints of the Max Planck Institute for Research on Collective Goods 2/2009). Bonn: Max Planck Institute for Research on Collective Goods. 
Holyoak, K. J. (1991). Symbolic connectionism: Toward third-generation theories of expertise. In K. A. Ericsson \& J. Smith (Eds.), Toward a general theory of expertise (pp. 301-336). Cambridge: Cambridge University Press.

Holyoak, K. J., \& Simon, D. (1999). Bidirectional reasoning in decision making by constraint satisfaction. Journal of Experimental Psychology: General, 128, 3-31.

Kahneman, D., \& Klein, G. A. (2009). Conditions for Intuitive Expertise: A Failure to Disagree. American Psychologist, 64, 515-526.

Klein, G. A. (1993). A recognition-primed decision (RPD) model of rapid decision making. In G. A. Klein, J. Orasanu, R. Calderwood, \& C. E. Zsambok (Eds.), Decision making in action: Models and methods (pp. 138-147). Norwood, NJ: Ablex.

Lesgold, A. M., Rubinson, H., Feltovich, P., Glaser, R., Klopfer, D., \& Wang, Y. (1988). Expertise in complex skills: Diagnosing X-ray pictures. In M. T. H. Chi, R. Glaser, \& M. J. Farr (Eds.), The Nature of Expertise (pp. 311-342). Hillsdale, NJ: Erlbaum.

Lichtenstein, S., \& Fischhoff, B. (1977). Do those who know more also know more about how much they know? Organizational Behavior \& Human Performance, 20, 159-183.

Luce, M. F., Bettman, J. R., \& Payne, J. W. (1997). Choice processing in emotionally difficult decisions. Journal of Experimental Psychology: Learning, Memory, and Cognition, 23, 384-405.

Luce, M. F., Payne, J. W., \& Bettman, J. R. (1999). Emotional trade-off difficulty and choice. Journal of Marketing Research, 36, 143-159.

Luce, M. F., Payne, J. W., \& Bettman, J. R. (2001). The impact of emotional tradeoff difficulty on decision behavior. In E. U. Weber, J. Baron, \& G. Loomes (Eds.), Conflict and tradeoffs in decision making (pp. 86-109). New York, NY: Cambridge University Press.

Ma, Y. (1998). Lay participation in criminal trials: A comparative perspective. International Criminal Justice Review, 8, 74-94.

Machura, S. (2001). Interaction between lay assessors and professional judges in German mixed courts. International Review of Penal Law, 72, 29.

Machura, S. (2007). Lay assessors of German administrative courts: Fairness, power-distance orientation, and deliberation activity. Journal of Empirical Legal Studies, 4, 331-363. 
Marchant, G., \& Robinson, J. (1999). Is knowing the tax code all it takes to be a tax expert? On the development of legal expertise. In R. J. Sternberg \& J. S. Horvath (Eds.), Tacit knowledge in professional practice: researcher and practitioner perspectives (pp. 3-20). Mahwah, NJ: Lawrence Erlbaum.

Marchant, G., Robinson, J., Anderson, U., \& Schadewald, M. (1991). Analogical transfer and expertise in legal reasoning. Organizational Behavior and Human Decision Processes, 48, 272-290.

Marchant, G., Robinson, J., Anderson, U., \& Schadewald, M. (1993). The use of analogy in legal argument: Problem similarity, precedent, and expertise. Organizational Behavior and Human Decision Processes, 55, 95-119.

Miles, M. B., \& Huberman, A. M. (1984). Qualitative data analysis. Beverly Hills, CA: Sage.

Naqvi, N., Shiv, B., \& Bechara, A. (2006). The role of emotion in decision making: A cognitive neuroscience perspective. Current Directions in Psychological Science, 15, 260264.

Nievelstein, F., van Gog, T., Boshuizen, H. P. A., \& Prins, F. J. (2010). Effects of conceptual knowledge and availability of information sources on law students' legal reasoning. Instructional Science, 38, 23-35.

Nisbett, R. E., Zukier, H., \& Lemley, R. E. (1981). The dilution effect: Nondiagnostic information weakens the impact of diagnostic information. Cognitive Psychology, 13, 248277.

Payne, J. W., Bettman, J. R., \& Johnson, E. J. (1992). Behavioral decision research: A constructive processing perspective. Annual Review of Psychology, 43, 87-131.

Pennington, N., \& Hastie, R. (1986). Evidence evaluation in complex decision making. Journal of Personality and Social Psychology, 51, 242-258.

Pennington, N., \& Hastie, R. (1988). Explanation-based decision making: Effects of memory structure on judgment. Journal of Experimental Psychology: Learning, Memory, and Cognition, 14, 521-533.

Pennington, N., \& Hastie, R. (1992). Explaining the evidence: Tests of the Story Model for juror decision making. Journal of Personality and Social Psychology, 62, 189-206.

Read, S. J., Vanman, E. J., \& Miller, L. C. (1997). Connectionism, parallel constraint satisfaction and gestalt principles: (Re)introducting cognitive dynamics to social psychology. Personality and Social Psychology Review, 1, 26-53. 
Reyna, V. F., \& Lloyd, F. J. (2006). Physician decision making and cardiac risk: Effects of knowledge, risk perception, risk tolerance, and fuzzy processing. Journal of Experimental Psychology: Applied, 12, 179-195.

Rogers, W. H. (1993). Regression standard errors in clustered samples. Stata Technical Bulletin, 13, 19-23.

Schwarz, N. (2002). Feelings as information: Judgments and processing strategies. In T. Gilovich, D. Griffin, \& D. Kahneman (Eds.), Heuristics and biases: The psychology of intuitive judgment (pp. 534-547). Cambridge: Cambridge University Press.

Schwarz, N., \& Clore, G. (1983). Mood, misattribution, and judgments of well-being: Informative and directive functions of affective states. Journal of Personality and Social Psychology, 45, 513-523.

Shafir, E., Simonson, I., \& Tversky, A. (1993). Reason-based choice. Cognition, 49, 11-36.

Shanteau, J. (1992). Competence in experts: the role of task characteristics. Organizational Behavior and Human Decision Processes, 53, 252-266.

Simon, D. (2004). A third view of the black box: cognitive coherence in legal decision making. University of Chicago Law Review, 71, 511-586.

Simon, D., Snow, C. J., \& Read, S. J. (2004). The redux of cognitive consistency theories: Evidence judgments by constraint satisfaction. Journal of Personality and Social Psychology, 86, 814-837.

Slovic, P., Finucane, M., Peters, E., \& MacGregor, D. G. (2002). The affect heuristic. In T. Gilovich, D. Griffin, \& D. Kahneman (Eds.), Heuristics and biases: the psychology of intuitive judgment (pp. 397-420). New York: Cambridge University Press.

Smith, H. D., Stasson, M. F., \& Hawkes, W. G. (1998). Dilution in legal decision making: Effect of non-diagnostic information in relation to amount of diagnostic evidence. Current Psychology, 17, 333-345.

Sonnentag, S. (2000). Expertise at work: Experience and excellent performance. International Review of Industrial and Organizational Psychology, 15, 223-264.

Spellman, B. A. (2010). Judges, expertise, and analogy. In D. Klein \& G. Mitchell (Eds.), The Psychology of Judicial Decision Making (pp. 149-163). Oxford: Oxford University Press.

Ste-Marie, D. M. (1999). Expert-novice differences in gymnastic judging: An informationprocessing perspective. Applied Cognitive Psychology, 13, 269-281. 
Thomas, C. (2010). Are Juries Fair? London : Ministry of Justice

Wessel, E., Drevland, G. C. B., Eilertsen, D. E., \& Magnussen, S. (2006). Credibility of the emotional witness: A study of ratings by court judges. Law and Human Behavior, 30, 221-230.

Zukier, H. (1982). The dilution effect: The role of the correlation and the dispersion of predictor variables in the use of nondiagnostic information. Journal of Personality and Social Psychology, 41, 1163-1174. 


\section{Appendix: Case 'A landlord causing a gas explosion'}

\section{Version 1 - low information amount:}

A is the owner of a block of flats that are rented. He wishes to renovate the building. The tenants resist his plans. This is why A and one of his friends get the idea of manipulating a gas main in the cellar in order for the tenants to leave out of fear. A acts upon his plan. A realizes that the gas explosion could lead to the death of the inhabitants. This outcome was not intended by A.

There is an explosion, the entire house collapses, six inhabitants are killed.

\section{Version 2 - high information amount:}

$\mathrm{A}$ is the owner of a block of flats that are rented. He wishes to renovate the building in order to sell it at a profit. The tenants resist his plans by refusing to move into a different apartment block that is also owned by him. A has therefore put his tenant under pressure in order to induce them to move out. He is unsuccessful. This is why A and one of his friends get the idea of manipulating a gas main in the cellar in order to cause an explosion, with the aid of a nightlight. They want to cause "the walls to shake", to "officially evacuate" the house or to induce tenants to leave out of fear. A acts upon his plan by removing plugs from the gas main. A realizes that the gas explosion could lead to the death of the inhabitants. This outcome was not intended by A.

There is an explosion, the entire house collapses, six inhabitants are killed.

Note. Underlines indicate the additional information. 